\title{
Hemşirelik Öğrencilerinin Sağlık Durumu Algılarının ve Sağlıklı Yaşam Biçimi Davranışlarının Belirlenmesi
}

\author{
Türkan Karaca'® ${ }^{1}$, Sinan Aslan²®
}

'Adıyaman Üniversitesi, Sağlık

Yüksekokulu Hemşirelik Bölümü, Adıyaman, Türkiye

²Batman Üniversitesi, Sağlık Yüksekokulu Hemşirelik Bölümü, Batman, Türkiye

Türkan Karaca, Doç. Dr. Sinan Aslan, Dr. Öğr. Üyesi

İletişim:

Doç. Dr. Türkan Karaca

Adıyaman Üniversitesi, Hemşirelik Bölümü,

Adıyaman, Türkiye

Tel: +90 $4162233800-4619$

E-Posta: turkan_20051@hotmail.com

Gönderilme Tarihi : 21 Nisan 2018

Revizyon Tarihi : 26 Mayıs 2018

Kabul Tarihi : : 30 Mayıs 2018

\section{ÖZET}

Giriş: Hemşirelik öğrencilerinin ileride etkin bakım veren hemşireler olabilmeleri için öncelikle kendilerinin sağlık algılarının farkına varmaları ve sağlıkı yaşam biç̧imi davranışlarına sahip olmaları gerekir.

Amaç: Bu tanımlayııı araştırmanın amacı, hemşirelik öğrencilerinin sağlık durumu algılamaları ile sağlıkı yaşam biçimi davranışlarııı belirlenmesidir.

Yöntem: Çalışmanın evreni 2016-2017 Öğretim Yılı Güz Yarı ylıına Adıyaman Üniversitesi Sağılık Yüksekokulu Hemşirelik Bölümü'nde okuyan 363 öğrencidir. Çalışmanın örneklemini araştırmaya ilişkin bilgi aldıktan sonra kendi rızasıyla araş̧ırmaya katılan ve veri toplama araçlarını tam olarak dolduran 293 öğrenci oluşturmuştur. Araştırmada veriler tanıtıı özellikler formu, Sağlık Durumunu Algılama Ölçeği ve Sağıkıı Yaşam Biçimi Davranışları Ölçeği II aracilığıyla toplanmıştır.

Bulgular: Öğrencilerin sağlıkı yaşam biçimi davranışları ölçek puan ortalamaları 134.15 18.14 'dır. Öğrencilerin sağlıklı yaşam biçimi davranışı ve sağlık durumlarını algılamaları incelendiğinde, sağlıkı yaşam biçimi ile sağlık durumunu algılama arasında istatistiksel olarak anlamlı bir fark bulunmuştur. Sağlık durumunu çok iyi algılayan öğrencilerin sağlıklı yaşam biçimi davranışı ölçeği toplam puanı daha yüksek olarak saptanmıştır.

Sonuç: Araştırmada hemşirelik öğrencilerinin sağıkılı yaşam biçimi davranışları puan ortalamalarının orta seviyenin üstünde olduğu ve ögrrencilerin ölçek puanı arttıkça kendi sağlık durumlarını daha iyi algıladıkları saptanmıştır. Hemşirelerin sağık durumlarını iyi algılamaları için hemşirelik eğitiminde yer alan derslerin olumlu sağlık davranışlarııı kazandırmaya yönelik düzenlenmesi önemlidir.

Anahtar sözcükler: Sağlıkı yaşam biçimi davranışları, sağlık algısı, sağlık davranışı, öğrenci hemşire

\section{DETERMINATION OF HEALTH STATUS PERCEPTIONS AND HEALTHY LIFE STYLE BEHAVIORS OF NURSING STUDENTS}

\section{ABSTRACT}

Background: In order for nursing students to become nurses who provide effective care in the future, they should be aware of specifically their own health perceptions and have healthy lifestyle behaviours.

Aim: This descriptive study aims to identify nursing students'health perceptions and their healthy lifestyle behaviours.

Method: Target population of the study was 363 students who were enrolled in the basic professional courses in the Nursing Department of Health High School at Adiyaman University in 2016-2017 academic year. The participants were 293 students who volunteered to participate in the study after they had been informed by the researcher and who fully completed the data collection forms. Data were collected through the Descriptive Features Form, the Health Perception Scale, and Healthy Lifestyle Behaviours Scale II.

Findings: Students'Healthy Lifestyle Behaviour mean score was found $136.12 \pm 19.16$. The study found a statistically significant relationship between students'healthy lifestyle behaviours and their health perceptions. It was also found that students who had high Healthy Lifestyle Behaviours total scale scores perceived their health state very well.

Conclusion: This study found that healthy lifestyle behaviour mean scores of nursing students were above average, and students'health perceptions were found to increase with the increase in the scale scores. It is important that the courses in nursing education curriculum aim to help students gain positive health behaviours so they can have good health perceptions.

Keywords: Healthy Lifestyle Behaviors, Health Perception, Health Behaviour, Nursing Students. 
ağlıklı yaşam, insanlık tarihi göz önüne alındığında üzerinde konuşulan en eski konulardan birisidir ve temel insan hakları içinde yer almaktadır (1). Bireylerin en temel sorumluluklarının biri, sağlık davranışları edinerek sağlıklı bir yaşam biçimi geliştirmek ve dolayısıyla akut/kronik hastalıklardan korunmaktır (2). Toplumdaki her bir kişinin sağlığını koruması ve yükseltmesi için sağlık davranışları edinerek kendilerinin "sağlıklı yaşam biçimlerini" geliştirmeleri önemlidir (3). Sağlıklı yaşam biçimi, kişilerin yaşam koşulları içinde kendi sağlığını korumaya ve yükseltmeye yönelik davranışları seçmesi ve günlük aktivitelerinde uygulamasıdır. Sağlıklı yaşam biçimi davranışları ise kişilerin seçtiği ve uyguladığı davranışların sağlıklarını korumalarını ve yükseltmelerini sağlayan davranışlar olması olarak tanımlanmaktadır. Sağııklı yaşam biçimi davranışları, beslenme, stresten uzak durma, fiziksel aktivite, manevi gelişim, kişilerarası iletişim ve bireyin sağlığını koruma ve yükseltmesine dair sorumlulukları yerine getirmelerini kapsar (4).

Yaşam biçimine bağlı gelişen bir çok hastalığın ve bu hastalıklar nedeniyle meydana gelen ölümlerin önüne geçilebilmesi için kişilerin sağlıklı yaşam biçimi davranışlarını edinmeleri elzemdir. Sağlık davranışlarının edinilmesi özellikle kronik hastalıkların engellenmesinde, kronik hastalıklarda yaşam kalitesinin yükseltilmesinde ve sağlıklı yaşlanmada çok önemlidir (5). Ayrıca bireylerin bu davranışları kazanması, gelişen hastalıkların tanı, tedavi ve bakım masraflarının da büyük oranda azalmasına neden olacaktır (6).

Kişilerin sağlıklı yaşam biçimi davranışlarını edinebilmesi için ilk önce kendilerinin yaşam biçimi davranışlarının ve kendi sağlıklarını nasıl algıladıklarının bilinmesi gerekmektedir. Kişilerin var olan yaşam biçimi davranışlarının bilimesiyle intiyaçlarına yönelik eğitim programları hazırlanabilir. Sağlıklı yaşam biçimi davranışlarının belirlenmesinde Pender ve arkadaşları'nın (1987) oluşturduğu sağlığı geliştirme modeli kapsamındaki temel kavram ve ilkeler rehber olarak alınmıştır. Sağlığı geliştirme modelinde bireylerin davranışlarını etkileyen öğrenme süreçleri önemlidir ve bu süreçte bireylere olumlu sağlık davranışları edinmelerini sağlayan eğitimin önemli olduğunu vurgular (7).

Literatürde hemşirelik öğrencilerinin sağlık durumları algısı ve sağlıklı yaşam biçimi davranışlarını araştıran çok az sayıda çalışma bulunmaktadır. Yapılan bu çalışmalarda öğrencilerin sağlık durumlarını olumlu algılamalarının sağlıklı yaşam biçimi davranışları edinmelerini de olumlu etkilediği saptanmıştır (1,8-10). Bununla birlikte bazı çalışmalarda ise öğrencilerin sağlık durumunu olumlu algılamalarına rağmen sağlık davranışlarını yaşam biçimi haline getiremedikleri bulunmuştur $(11,12)$.

Hemşireler sağlık hizmetleri içinde sağlığın korunması ve sürdürülmesinde önemli rollere sahiptir. Hemşirelik öğrencilerinin ileride bu anahtar rollerini yerine getirebilmesi için için öncelikle kendilerinin sağlık algılarının farkına varmaları ve sağlıklı yaşam biçimi davranışları edinmeleri gerekmektedir (10). Hemşirelik öğrencilerinin sağlık algısı ve sağlıklı yaşam biçimi davranışlarının belirlenmesi, mevcut durum üzerinde düşünülmesine ve bu alandaki ihtiyaçların saptanmasına imkan verecektir. Bu duruma ek olarak eğitimcilerin, hemşirelik öğrencilerinin sağlık algılarına ve sağlıkı yaşam biçimi davranışlarına dair bilgi sahibi olması gerekmektedir. Böylece, hemşirelik eğitim içeriğinin, öğrencilerde sağlık algısı geliştirmelerine ve dolayısıyla olumlu sağlık davranışlarını yaşam biçimine aktarmalarına katkı sağlanacak şekilde düzenlenmesine katkı sağlanacaktır.

\section{Yöntem}

\section{Araştırmanın amacı}

Bu tanımlayıcı araştırma, hemşirelik öğrencilerinin sağlık durum algılarını ve sağlıklı yaşam biçimi davranışlarını değerlendirmek amacıyla yapılmıştır.

\section{Araştırma soruları}

1. Hemşirelik öğrencilerinin sağlıklı yaşam biçimi davranışları II ölçek puan ortalamaları nedir?

2. Hemşirelik öğrencilerinin sağlıklarını algılama durumları nedir?

3. Hemşirelik öğrencilerinin sağlık durumu algıları ile sağlıklı yaşam biçimi davranışları Il toplam puanları arasında istatiksel olarak anlamlı bir fark var mıdır?

\section{Araştırmanın tipi}

Araştırma, hemşirelik öğrencilerinin sağlık algısı ile sağlıklı yaşam biçimi davranışları arasındaki ilişkisinin belirlenmesi amacıyla tanımlayıcı türde kesitsel bir çalışma olarak planlanmıştır.

\section{Araştırmanın yeri}

Çalışmanın evreni 2016-2017 Öğretim Yılı Güz Yarı yılında Adıyaman Üniversitesi Sağlık Yüksekokulu Hemşirelik Bölümü'nde okuyan 363 öğrencidir. Çalışmanın örneklemini araştırmaya ilişkin bilgi aldıktan sonra kendi rızasıyla araştırmaya katılan ve veri toplama araçlarını tam olarak dolduran 293 öğrenci oluşturmuştur. 
Veri toplama araçları

Araştırmada veriler tanıtıcı özellikler formu, Sağlık Durumunu Algılama Ölçeği ve Sağlıklı Yaşam Biçimi Davranışları Ölçeği II aracılığıyla toplanmıştır.

Tanıtıcı özellikler formu, öğrencilerin bazı tanımlayıcı özelliklerini saptamak amacıyla belirlenmiş toplam 9 soru içermektedir. Tanıtıcı özellikler formunda öğrencilerin sınıf, yaş, cinsiyet, medeni durum, çalışma durumu, kronik hastalık durumu, genel/ağız sağlığı durumu, fiziksel aktivite yapma durumu, sigara kullanma alışkanlıkları sorgulanmıştır.

Sağlık Durumunu Algılama Ölçeği ilk defa 1978 yılında Davis, Avery ve Donald tarafından oluşturulmuştur. Esin (1997) tarafından ilgili ölçeğin ülkemizde geçerlik ve güvenirlik çalışması yapılmıştır. Sağlık durumunu algılama ölçeğinde, bireyin mevcut sağlığını nasıl düşündüğü saptanmaya çalışılmıştır. Çok iyi (1), iyi (2), kötü (3) ve çok kötü (4) seçeneklerinin olduğu ölçekte, en yüksek puan bir, en düşük puan dört olarak belirtilmiştir. Sağlığın Önemi Ölçeği'nin Cronbach Alpha katsayısı 0,89'dur (13).

Pender ve arkadaşları tarafından ilk defa 1987 yılında Sağlıklı Yaşam Biçimi Ölçeği geliştirilmiştir. Esin (1997) tarafından ilgili ölçeğin ülkemizde geçerlik ve güvenirlik çalışması yapılmıştır. Daha sonra Walker ve Hill-Polerecky (1996) bu ölçeği tekrar düzenleyerek Sağlıklı Yaşam Biçimi Davranışları II (SYBD II) olarak adlandırmışlardır. Bahar ve arkadaşları (2008) tarafından SYBD II ölçeğinin geçerlik ve güvenirlik çalışması yapmıştır. Sağlıklı Yaşam Biçimi Ölçeği II, 4'lü likertli 52 maddeli ve 'hiçbir zaman', 'bazen', 'sık sık've 'düzenli olarak'seçeneklerini içeren bir ölçektir. Ölçek 'sağlık sorumluluğu', 'fiziksel aktivite', 'beslenme', 'manevi gelişim', 'kişilerarası ilişkiler've "stres yönetimi" başlıkları altında altı alt ölçekten oluşmaktadır. Ölçekten alınabilecek en yüksek puan 208, en düşük puan 52 olarak belirlenmiştir. SYBDÖ II'nin Cronbach Alpha katsayısı 0,92'dir. Ölçekten alınan toplam puan yükseldikçe, öğrencinin sağlıklı yaşam biçimi davranışları geliştirdiği düşünülmektedir $(6,14)$.

\section{Araştırmanın uygulanması}

Araştırma öğrencilerin eğitim-öğretim yılının ilgili güz döneminin ilk haftası (26-30 Eylül 2016) yürütülmüştür. Öğrencilerin öğrenim gördükleri sınıflarda veri toplama formları dağıtılmadan önce öğrencilere araştırmaya ilişkin bilgiler verilmiştir. Daha sonra kendi rızasıyla araştırmaya katılmaya kabul eden katılımcılara aydınlatılmış yazılı onam formunu imzalamaları söylenmiştir. Aydınlatılmış yazılı onam formunu dolduran öğrencilere tanıtıcı özellikler formu, Sağlık Durumunu Algılama Ölçeği ve SYBDÖ II aynı anda verilmiş ve öğrencilerden ilgili formları eksiksiz doldurmaları istenmiş̧tir.

\section{Verilerin değerlendirilmesi}

Araştırmada anket formları ile toplanan veriler bilgisayara ortamına aktarılmış ve istatistiksel testler SPSS for Windows 16 istatistik paket program ile yapılmıştır. Araştırmada ölçeklerden alınan puanlar bağımlı değişkenleri, tanıtıcı özellikler formunda yer alan veriler ise bağımsız değişkenleri göstermektedir. Mann-Whitney U testi (parametrik varsayımlar olmadığı için) iki bağımsız grup için istatistiksel hesaplamalarda, Kruskal-Wallis testi (parametrik varsayımlar olmadığı için) ise ikiden fazla bağımsız grubun istatiksel hesaplamalarında kullanılmıştır. Ayrıca, verilerin analizinde yüzdelik hesapları, ortanca, minimum, maksimum kullanılmıştır.

\section{Araştırmanın etik yönü}

Araştırmanın uygulanabilmesi için Adıyaman Üniversitesi Girişimsel Olmayan Araştırmalar Etik Kurulu'ndan izin alınmıştır. Adıyaman Üniversitesi Sağlık Yüksekokulu Hemşirelik Bölümü Başkanlığı'ndan çalışmanın yapılabilmesi için yazılı izin alınmıştır. Araştırmaya kendi rızasıyla katılan Adıyaman Üniversitesi Sağlık Yüksekokulu Hemşirelik Bölümü öğrencilerinden yazılı onam alınmıştır. Çalışmanın yapılabilmesi için ölçeklerin kullanım izinleri alınmıştır.

\section{Bulgular}

Araştırmaya katılan öğrencilerin tanıtıcı özellikleri incelendiğinde, öğrencilerin \%52.5'i 21-23 yaş aralığındadır ve hemen hemen hepsinin bekar (\%99.0) olduğu görülmektedir. Öğrencilerin çoğunluğu kız olup (\%75.1), hemşire olarak herhangi bir yerde çalışmamaktadır (\%96.9). Öğrencilerin yarısı (\%55.3) herhangi bir spor aktivitesi ile uğraşmamaktadır. Öğrencilerin çoğunluğu (\%83.6) sigara kullanmamakta ve herhangi bir kronik hastalığa sahip değildir (\%90.8). Öğrencilerin \%53.9'u her rahatsızlık durumunda, \%42.7'si önemli hastalık durumunda sağlık merkezine gitmektedir. Belirli aralıklarla sağlık kontrolüne giden öğrencilerin oranı ise sadece \%3.4'tür (Tablo 1).

Tablo 2'te öğrencilerin SYBD II ölçeği ve alt ölçeklerinin istatistiksel analizleri verilmiştir. Öğrencilerin SYBDÖ II puan ortalamaları 134.15 \pm 18.14 'dır. Öğrenci puanlarının medyan değeri 134 olup minimum puan 69, maksimum puan 194'tür. 
Tablo 1. Öğrencilerin tanıııcı özellikleri

\begin{tabular}{lcc} 
Tanıtıcı Özellikler (n=293) & Sayı & $\%$ \\
\hline Sınıflar & 43 & 15.0 \\
Birinci Sınıf & 82 & 28.0 \\
İkinci Sınıf & 84 & 28.5 \\
Üçüncü Sınıf & 84 & 28.5 \\
Dördüncü Sınıf & & \\
\hline Yaş Grupları & 93 & 31.7 \\
17- 20 & 154 & 52.5 \\
$21-23$ yaş & 46 & 15.8 \\
$24-30$ & & \\
Cinsiyet & 220 & 75.1 \\
Kız & 73 & 24.9 \\
Erkek & & \\
\hline Medeni Durumu & & \\
Bekâr & 290 & 99.0 \\
Evli & 3 & 1.0 \\
\hline Hemşire Olarak Çalışma Durumu & & \\
Evet & & \\
Hayır & & \\
\hline & & \\
\hline
\end{tabular}

\section{Spor Yapma Durumu}

Her gün $30 \mathrm{dk}$ yürüme

Düzenli egzersiz yapma 18

31.1

Amatör olarak bir spor dalı ile uğraşma

Herhangi bir spor aktivitesi yapmama

162

\section{Sigara Kullanma Durumu}

Günde 1-10 adet

Günde 1 paket

Günde 1 paketten fazla

Kullanmama

\section{Kronik Hastalığa Sahip OIma}

Evet

Hayır

266

90.8

\section{Sağlık Merkezine Gitme Sıklığı}

Her hastalandığında

Ciddi hastalık durumunda

Belirli aralıklarla

11
Tablo 3'de öğrencilerin sağlık durumunu algılamalarının sınıflara göre karşılaştırılması görülmektedir. Tabloda, birinci sınıf öğrencilerinin \%62.7'si, ikinci sınıf öğrencilerinin \%75.7'si, üçüncü sınıf öğrencilerinin \%75.8'i, dördüncü sınıf öğrencilerinin \%75.9'u sağılığını 'iyi'olarak algıladıklarını bildirmiştir ve sınıflar arasında anlamlı bir fark vardır $(p=.001)$.

Tablo 4'te öğrencilerin sağlık durumunu algılamalarının SYBD II ölçeği puan ortalamalarına göre karşılaştırılması görülmektedir. Sağlık durumunu 'çok iyi' olarak algılayan

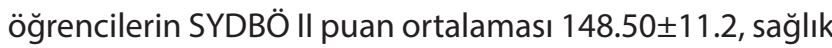
durumunu 'çok kötü' olarak algılayan öğrencilerin SYDBÖ Il puan ortalaması $105.15 \pm 20.2$ bulunmuştur. Öğrencilerin sağlık durumu algıları ile SYBDÖ II toplam puanları arasında istatiksel olarak anlamlı bir fark saptanmıştır ( $p=.001)$. Sağlık durumunu çok iyi algılayan öğrencilerin SYBDÖ ॥ toplam puanı daha yüksek olarak saptanmıştır.

Tablo 2. Öğrencilerin SYBD II ölçeği ve alt ölçeklerinin istatistiksel analizleri

\begin{tabular}{lccccc} 
SYBD II Alt Ölçekleri & $\boldsymbol{X} \pm$ SS & Medyan & Min. & Max. & Sayı \\
\hline Sağlık Sorumluluğu & $24.01 \pm 3.48$ & 24.00 & 10 & 37 & 293 \\
Fiziksel Aktivite & $17.95 \pm 3.77$ & 18.00 & 9 & 31 & 293 \\
Beslenme & $22.50 \pm 6.22$ & 22.00 & 10 & 60 & 293 \\
Manevi Gelişim & $28.80 \pm 3.19$ & 27.00 & 15 & 52 & 293 \\
Kişiler arası Il lişkiler & $28.22 \pm 5.05$ & 28.00 & 8 & 37 & 293 \\
Stres Yönetimi & $18.70 \pm 4.83$ & 19.00 & 9 & 32 & 293 \\
SYBD II Ölçeği & $\mathbf{1 3 4 . 1 5 \pm 1 8 . 1 4}$ & $\mathbf{1 3 4 . 0 0}$ & $\mathbf{6 9}$ & $\mathbf{1 9 4}$ & $\mathbf{2 9 3}$
\end{tabular}

Tablo 3. Öğrencilerin Sağlık Durumunu Algılamalarının Sinfilara Göre Karşılaştırlması $(n=293)$

\begin{tabular}{lccccccccccc}
\multicolumn{10}{c}{ Sağlık Durumunu Algılama } \\
\hline & \multicolumn{1}{c}{ Çok iyi } & \multicolumn{2}{c}{ lyi } & \multicolumn{1}{c}{ Kötü } & \multicolumn{3}{c}{ Çok kötü } & \\
\hline Sınıf & Sayı & $\%$ & Sayı & $\%$ & Sayı & $\%$ & Sayı & $\%$ & \\
\hline 1. Sınıf & 10 & 23.2 & 27 & 62.7 & 6 & 13.9 & 0 & 0.0 & \\
2. Sınıf & 15 & 18.5 & 63 & 75.7 & 4 & 4.8 & 0 & 0.0 & x2 $=\mathbf{1 5 . 0 2}$ \\
3. Sınıf & 8 & 9.5 & 64 & 75.8 & 9 & 9.6 & 2 & 5.1 & $\boldsymbol{p}=.001$ \\
4. Sınıf & 15 & 15.2 & 65 & 75.9 & 3 & 5.6 & 2 & 5.1 &
\end{tabular}

Tablo 4. Öğrencilerin sağlık durumunu algılamalarının SYBD || ölçeği puan ortalamalarına göre karşıllaştıııması $(n=293)$

\begin{tabular}{lcc} 
Sağlık Algısı $\boldsymbol{n}$ & $\boldsymbol{X} \pm$ SS & \\
\hline Çok iyi 48 & $148.50 \pm 11.2$ & \\
lỳi 219 & $130.81 \pm 15.4$ & $\mathbf{F}=\mathbf{1 0 . 6 5}$ \\
Kötü 22 & $110.12 \pm 13.2$ & $\mathbf{p}=. \mathbf{0 0 1}$ \\
Çok Kötü 4 & $105.15 \pm 20.2$ &
\end{tabular}




\section{Tartışma}

SYBD II ölçeğinden elde edilebilecek tavan puanın 208 olduğu düşünüldüğünde, öğrencilerin SYBDÖ puanlarının orta seviyenin üstünde olduğu (134.15 \pm 18.14$)$ söylenebilir. Yurt dışında yapılan çalışmalar incelendiğinde, Al-Kandari ve Vidal'ın (2006) yaptığı çalışmada, hemşirelik öğrencilerinin ölçek puan ortalaması 128.16, Hawks ve arkadaşlarının (2002) Japonyalı öğrencilerle yaptığı çalışmada ölçek puan ortalamaları 125.76, Hui (2002) tarafından Hong Kong'da bir üniversitede öğrenim gören öğrenciler ile yaptıkları araştırmada ölçek puan ortalamaları 116.28 olarak bulunmuştur (15-17). Bu çalışmalara göre, araştırmamıza katılan hemşirelik öğrencilerinin ölçek puan ortalamalarının daha yüksek ve dolayısıyla daha sağlıklı yaşam biçimine sahip oldukları düşünülebilir.

Ülkemizde yapılan çalışmalar incelendiğinde, Yılmazel ve ark. (2013) hemşirelik öğrencileri ile yaptığı çalışmada, öğrencilerin SYBD ölçeği puan ortalaması $121,57 \pm 19,65$ olarak belirtilmiştir (18). Genç ve arkadaşlarının (2015) SYBD ölçeği kullanarak hemşirelik öğrencileri ile gerçekleştirdiği araştırmada, öğrencilerin SYBD ölçek puan ortalaması $121,67 \pm 20,18$ olarak bulunmuştur (19). Şen ve arkadaşları (2017) sağlık hizmetlerinde okuyan öğrencilerin SYBD II puan ölçek ortalamalarını 118,0 $\pm 21,0$ olarak bulmuştur (20). Hemşirelik öğrencileri ile yapılan diğer çalışmalarda da benzer şekilde öğrencilerin SYBDÖ II puan ortalamalarının orta seviyenin üstünde olduğu söylenebilir (8,21-25). Bu durum ülkemizde yürütülen hemşirelik müfredatının temel olarak benzer olmasından kaynaklanabilir.

Öğrencilerin sağlık durumunu algılamalarının sınıflara göre karşılaştırılması incelendiğinde, üst sınıflara geçtikçe sağılığını 'iyi' olarak algılayan öğrencilerin sayısı artmaktadır ve sınıflar arasında anlamlı bir fark vardır $(p=.001)$. $\mathrm{Bu}$ durum hemşirelik öğrencilerin sağlıklı yaşam biçimi ölçek ortalamalarının üst sınıflara gittikçe yükselmesi ile ilişkilendirilebilir $(3,11,24)$. Alpar ve arkadaşlarının (2008) hemşirelik eğitiminin öğrencilerin sağlıklı yaşam biçimi davranışlarına etkisini belirlemek amacıyla yaptıkları çaIışmada öğrencilerin SYBD II ölçek puanların ortalamaları son yılda ilk yıla göre anlamlı şekilde bir artış göstermiştir
(26). Bu bilgiye ek olarak hemşirelik öğrencilerinin örneklem grubunu oluşturduğu çalışmalarda, 'sağlığı koruma ve geliştirme,' 'sağlıklı yaşam', 'sağlık ve yaşam' gibi dersleri alan hemşirelik öğrencilerinin ölçek puan ortalamaları bu dersleri almayan öğrencilerin ortalama puanlarından daha yüksek bulunmuştur $(8,22,23,27-29)$. Bu durumun nedeni ilgili derslerinin doğrudan sağlığını koruma ve geliştirmeye yönelik bilgi ve uygulamaları içermesinden kaynaklanabilir.

Sağlık durumunu çok iyi algılayan öğrencilerin SYBD ölçeği toplam puanı daha yüksektir ve öğrencilerin sağlık durumu algıları ile SYBDÖ II toplam puanları arasında istatiksel olarak anlamlı bir fark saptanmıştır $(p=.001)$. Literatür incelendiğinde, Zaybak ve Fadıloğlu'nun (2004) yaptığı araştırmada öğrencilerin gelecek yıllarda sağlığını kontrol edebilme inancındaki artış SYBD puan ortalamasının da doğru orantılı olarak artırdığını ortaya koymuştur(30). Hemşirelik öğrencileri ile yapılan benzer çalışmaların sonuçlarında da öğrencilerin sağlık durumlarını olumlu algılamalarının sağlıklı yaşam biçimi davranışları edinmelerini de olumlu etkilediği saptanmıştır $(1,9)$. Çalışmamızın sonuçları yapılan diğer çalışma sonuçları ile örtüşerek, öğrencilerin kendi sağlıklarını olumlu algılamaları, sağlıklarını geliştirmek için önemli bir güç olarak sağlık davranışlarının kazanılmasında etkili olduğunu göstermektedir.

\section{Sonuç ve öneriler}

Araştırmamızda hemşirelik öğrencilerinin SYBDÖ II puanlarının orta seviyenin üstünde olduğu (134.15 \pm 18.14$)$ ortaya konmuştur. Öğrencilerin sağlık durumu algıları ile SYBD ölçeği toplam puanları arasında istatiksel olarak anlamlı bir ilişki saptanmıştır $(p=.001)$. Sağlık durumunu çok iyi algılayan öğrencilerin SYBD ölçeği toplam puanı daha yüksek olarak saptanmıştır. Sağlığın yükseltilmesinde, hemşirelerin olumlu sağlık algısı geliştirilmeleri ve dolayısıyla sağlıklı yaşam biçimine sahip olmaları için hemşirelik müfredatının bu davranışları kazandırmaya yönelik düzenlenmesi gerekmektedir. Ayrıca, 'sağlığı koruma ve geliştirme,' 'sağlıklı yaşam', 'sağlık ve yaşam'gibi derslerin müfredatta yer alması önerilmektedir. 


\section{Kaynaklar}

1. Açıksöz $S$, Uzun Ş, Arslan, F. Hemşirelik öğrencilerinin sağlıklı yaşam biçimi davranışları arasındaki ilişkinin incelenmesi. Gülhane Tıp Derg 2013;55:181-7. [CrossRef]

2. Hekimoğlu L, Şensoy N. Aile sağlığı merkezine başvuran hastaların sağlık denetim odağı algılama düzeyleri ve sağlık davranışlarına etkisi. Euras J Fam Med 2014;3:157-62. Erişim: http://ejfm.trakya. edu.tr/userfiles/2014/December/6-levent-hekimoglu.pdf

3. Beydağ KD, Uğur E, Sonakın C, Yürügen B. Sağlık ve yaşam dersinin üniversite öğrencilerinin sağlıklı yaşam biçimi davranışlarına etkisi. GÜSD 2014;3:599-609.

4. Walker SN, Sechrist KR, Pender NJ. The health-promoting lifestyle profile: Development and psychometric characteristics. Nurs Res 1987;36:76-81. [CrossRef]

5. Cihangiroğlu Z, Deveci SE. Fırat Üniversitesi Elazığ Sağlık Yüksekokulu öğrencilerinin sağlıklı yaşam biçimi davranışları ve etkileyen faktörler. Firat Tıp Derg 2011;16:78-83. Erişim: http://docplayer. biz.tr/21069758-Firat-universitesi-elazig-saglik-yuksekokuluogrencilerinin-saglikli-yasam-bicimi-davranislari-ve-etkileyenfaktorler.html

6. Bahar Z, Beşer A, Gördes N, Ersin F, Kısal A. Sağlıklı yaşam biçimi davranışları ölçeği II'nin geçerlik ve güvenirlik çalışması. CÜ Hem YO Derg 2008;12:1-13. Erişim: http://eskidergi.cumhuriyet.edu.tr/ makale/1723.pdf

7. Li J, Phowdthavee N. Does more education lead to better health habits? Evidence from the school reforms in Australia. Soc Sci Med 2014;127:83-91. [CrossRef]

8. Ayaz $S$, Tezcan $S$, Akıncı F. Hemşirelik yüksekokulu öğrencilerinin sağlığı geliştirme davranışları. CÜ Hem YO Derg 2005;9:26-34. Erişim: http://eskidergi.cumhuriyet.edu.tr/makale/1149.pdf

9. Tuğut N, Bekar M. Üniversite öğrencilerinin sağlığı algılama durumları ile sağlıklı yaşam biçimi davranışları arasındaki ilişki. Atatürk Üniv Hem YO Derg 2008;11:17-26. Erişim: https://dergipark. org.tr/download/article-file/29418

10. Bryer J, Cherkis F, Raman J. Health-promotion behaviors of undergraduate nursing students: a survey analysis. Nurs Educ Perspect 2013;34:410-5. [CrossRef]

11. Aksoy $T$, Uçar H. Hemşirelik öğrencilerinin sağlıklı yaşam biçimi davranışları. Hacettepe Üniv Sağlık Bilim Fak Hem Derg 2014;1:5367. Erişim: https://dergipark.org.tr/download/article-file/88641

12. Ünalan D, Şenol V, Öztürk A, Erkorkmaz Ü. Meslek yüksekokullarının sağlık ve sosyal programlarında öğrenim gören öğrencilerin sağlıklı yaşam biçimi davranışları ve öz-bakım gücü düzeyleri arasındaki ilişkinin incelenmesi. Inönü Üniv Tıp Fak Derg 2007;14:101-9. Erişim: https://www.researchgate.net/publication/314451082_Meslek_ Yuksekokullarinin_Saglik_ve_Sosyal_Programlarinda_Ogrenim_ Goren_Ogrencilerin_Saglikli_Yasam_Bicimi_Davranislari_ve_OzBakim_Gucu_Duzeyleri_Arasindaki_lliskinin_Incelenmesi

13. Esin N. Endüstriyel alanda çalışan işçilerin sağlık davranışlarının saptanması ve geliştirilmesi. İstanbul Üniversitesi Sağlık Bilimleri Enstitüsü. Hemşirelik Programı Doktora Tezi. İstanbul; 1997.

14. Walker SN, Hill-Polerecky DM. Psychometricevaluation of the health promoting lifestyle profile II. Unpublished Manuscript. University of Nebraska Medical Center; 1996.
15. Al-Kandari F, Vidal VL. Correlation of the health-promoting lifestyle, enrollment level and academic performance of college of nursing students in Kuwait. Nurs Health Sci 2007;9:112-9. [CrossRef]

16. Hawks RS, Madanat HN, Merill RM, Goudy MB, Miyagwa TA. Crosscultural comparison of health promoting behaviours among college students. J Health Educ 2002;5:84-92.

17. Hui WHC. The health-promoting lifestyles of undergraduate nurses in Hong Kong. J Prof Nurs 2002;18:101-11. [CrossRef] https://doi. org/10.1053/jpnu.2002.32346

18. Yılmazel G, Çetinkaya F, Nacar N. Hemşirelik öğrencilerinde sağlığı geliştirme davranışları. TAF Prev Med Bull 2013;12:261-70. [CrossRef]

19. Genç F, Yeşilyurt G, Eroğlu G, Altıparmak A, Polat A, Söğüt D. Sağlık Bilimleri Fakültesi Öğrencilerinin sağlığı geliştirme davranışlarının belirlenmesi. GÜSDg 2015;4:15-27. Erişim: https://dergipark.org.tr/ download/article-file/220164

20. Şen MA, Ceylan A, Kurt ME, Palancı Y, Adın C. Sağlık hizmetleri meslek yüksekokulu öğrencilerinin sağlıklı yaşam biçimi davranışları ve etkileyen faktörler. Dicle Tıp Derg 2017;44:1-12. [CrossRef]

21. Özbaşaran F, Çetinkaya A, Güngör N. Celal Bayar Üniversitesi Sağlık Yüksekokulu öğrencilerinin sağlık davranışları. Atatürk Üniv Hem YO Derg 2004;7:43-55. Erişim: https://dergipark.org.tr/download/ article-file/29241

22. Çelik GO, Malak AT, Bektaş M, Yılmaz D, Yümer SA, Öztürk Z, Demir E. Sağlık yüksekokulu öğrencilerinin sağlığı geliştirme davranışlarını etkileyen etmenlerin incelenmesi. Anatol J Clin Investig 2009;3:164-9.

23. Kocaakman $M$, Aksoy G, Eker HH. İstanbul ilindeki hemşirelik yüksekokulu öğrencilerinin sağılıkı yaşam biçimi davranışları. SDÜ Tıp Fak Derg 2010;17:19-24.

24. İlhan N, Batmaz M, Akhan LU. Üniversite öğrencilerinin sağlıklı yaşam biçimi davranışları. Maltepe Üniv Hem Bil Sanat Derg 2010;3:34-44.

25. Özyazıcıoğlu N, Kılıç M, Erdem N, Yavuz C, Afacan S. Hemşirelik öğrencilerinin sağlıklı yaşam biçimi davranışlarının belirlenmesi. Uluslararası İnsan Bil Derg 2011;8:278-332.

26. Ecevit Alpar Ş, Şenturan L, Karabacak, U, Sabuncu N. Change in the health promoting lifestyle behaviour of Turkish University nursing students from beginning to end of nurse training. Nurs Educ Pract 2008;8:382-8. [CrossRef]

27. Ata EE. Hemşirelik Programının Öğrencilerde Sağlıklı Yaşam Biçimi Davranışlarının Geliştirilmesine ve Yaşam Kalitesine Etkisi. Cumhuriyet Üniversitesi Sağlık Bilimleri Enstitüsü, Yüksek Lisans Tezi. Sivas; 2008.

28. Şemin I, Tengiz Fl. Effect of health education on healthy lifestyle behavior. Turkiye Klinikleri J Health Sci 2016;1:194-200. [CrossRef]

29. Tambağ H, Turan Z. Öğrencilerin sağlıklı yaşam biçimi davranışlarına halk sağlığı hemşireliği dersi'nin etkisi. Hem Araş Geliş Derg 2012;1:46-55. Erişim: http://hemarge.org.tr/ckfinder/userfiles/ files/2012/2012-vol14-sayi1-266.pdf

30. Zaybak A, Fadıloğlu Ç. Üniversite öğrencilerinin sağlığı geliştirme davranışları ve bu davranışları etkileyen etmenlerin belirlenmesi. Ege Üniv Hem YO Derg 2004;20:77-95. Erişim: https://dergipark.org. tr/download/issue-file/8593 